\title{
DETECTION OF INTERCELLULAR ADHESION GENES (ICA) IN STAPHYLOCOCCUS AUREUS CAUSING IMPLANT ASSOCIATED INFECTIONS
}

\author{
PRASANTH P. a $^{*}$, SARAVANAKUMARI P. \\ aResearch and Development Centre, Bharathiar University, Coimbatore, Tamil Nadu, India, bepartment of Microbiology, Sree Narayana \\ Guru College, Coimbatore, Tamil Nadu, India \\ Email: prasanth_pal@yahoo.com \\ Received: 17 Jun 2017 Revised and Accepted: 21 Sep 2017
}

\section{ABSTRACT}

Objective: The complications related to implant associated infections in post-angioplasty patients were considered to increase due to biofilm formation.

Methods: Genes responsible for the biofilm formation in the target organisms was investigated in the present study. The presence of the intercellular adhesion biofilm genes (icaA, icaB and icaD) was determined by the Polymerase Chain Reaction method. As preliminary investigations, standard tests, exit-site challenge test and microtitre plate method were used to study the biofilm efficiency of five different test organisms.

Results: Exit-site challenge test, was used to identify the ability of test organisms to grow on a bio-materials used in the study. Among the five selected test organisms, Staphylococcus aureus showed the highest ability to colonize the stent materials with in $24 \mathrm{~h}$ to $48 \mathrm{~h}$. In microtitre plate method, Staphylococcus aureus and Staphylococcus epidermidis showed high biofilm forming index values of 0.29 and 0.27 respectively. Biofilm gene studies using PCR revealed the presence of all the three ica genes (Ica A, Ica D and, Ica B) in Staphylococcus aureus. The present research finding has great significance in the treatment to implant associated infections.

Conclusions: The results suggest that the virulence factors contributing to the development of infections can be revealed by understanding the presence of biofilm expression genes in the target organisms. This would also prevent dissemination of virulent bacteria in the health care centre; method also considered significant to detect healthy carriers of slime-producing staphylococci.

Keywords: Biofilm, Exit-site, Staphylococcus aureus, icaR locus, Polymerase chain reaction

(C) 2017 The Authors. Published by Innovare Academic Sciences Pvt Ltd. This is an open access article under the CC BY license (http://creativecommons.org/licenses/by/4.0/) DOI: http://dx.doi.org/10.22159/ijpps.2017v9i11.20789

\section{INTRODUCTION}

Biofilms are three-dimensional mosaic microbial consortia which adhere and accumulate at implant surfaces using their extracellular polymers called glycocalyx [1]. Biofilm forming methicillin-resistant Staphylococcus aureus (MRSA) is considered as an alarming increase in hospital environment since it causes serious problem [2]. Another organism Staphylococcus epidermidis are also reported to be associated with medical implant-related infections. S. aureus together with $S$. epidermidis is the organism most frequently isolated from medical implant-related infections. In conditions, Staphylococcus spp. strains are able to form biofilms on polymer surfaces and it is suggested that this property contributes significantly to the pathogenesis of staphylococcal infections [3]. Biofilms are considered as the highly consolidated structures developed on most frequently used medical implants like stents, catheters, prosthesis and dentures [4]. Biofilms are a population of multi-layered cells growing on a surface and is enclosed in the exopolysaccharide matrix [5]. Increasing numbers of organisms are genetically resistant to antibiotics. Even the organisms which are not genetically resistant to antibiotics are reported to be highly resistant when they are in the form of biofilms [6]. Development of a biofilm is considered as series of steps like adhesion, colonization, accumulation, maturation and release. The bacteria adhere to a surface mediated by a capsular antigen, namely the capsular polysaccharide [7], and then the bacteria multiply to form a multi-layered biofilm. This with the production of polysaccharide intercellular adhesin (PIA) helps in mediating cell to cell adhesion [8].

Biofilm formation is regulated by the expression of polysaccharide intracellular adhesion (PIA) property of bacteria. The synthesis of PIA is encoded by the products of the chromosomal ica-genes (intercellular adhesion), which are organized in an operon structure [9]. The operon contains the ica ADBC genes, in addition to the icaR gene which exerts a regulatory function and is transcribed in the opposite direction [10]. Once this operon is activated, four proteins are transcribed, Ica A, Ica D, Ica B and Ica C, which are necessary for the synthesis of PIA [11]. Due to the above described complications caused by biofilm producing organism in the indwelling medical devices, early detection of biofilm expressing genes in the target organism shall be considered as the essential approach towards the prevention and management of device-associated infections. Identification of the significant genes (icaA, icaB and icaD) coding for the biofilm expressions was considered as the primary objective in the present research.

\section{MATERIALS AND METHODS}

About five different bacterial test cultures isolated from the biological specimens were procured from a diagnostic laboratory at Coimbatore, Tamil Nadu, India. Aerobic, biofilm producing organisms, Staphylococcus epidermidis (ATCC 35984), Staphylococcus aureus (ATCC 29213), Escherichia coli (ATCC 43894), Proteus mirabilis (ATCC 49565) and Pseudomonas aeruginosa (ATCC 700829) were selected for the study, mainly based on their ability to surface colonize on the stent materials. Each culture was sub cultured, maintained in their selective media and reconfirmed by standard biochemical methods.

All the dehydrated biological media used in the research were commercially procured from HiMedia, Mumbai, India. All the other chemicals were procured from Sigma-Aldrich, India. The entire research work was carried out from October 2016 to March 2017.

\section{Surface colonizing ability of test organisms: Exit-site challenge test}

Exit-site challenge test [12] was performed to investigate the ability of the organism to grow both external and inner surface of braided stents. In this method, Iso-sensitest semi solid Agar was used for this analysis. Media surface was inoculated with $100 \mu \mathrm{l}$ of test organisms [Staphylococcus aureus, Staphylococcus epidermidis, Escherichia coli, Proteus mirabilis and Pseudomonas aeruginosa]. Each braided stents with pre-measure size of $15 \mathrm{~mm}$ in length was spliced under sterile 
conditions. All the stent samples are sterilized and inserted onto the semi-solid media with half of the portion projecting outside. The stents should be inserted through the inoculated area and incubated at $37^{\circ} \mathrm{C}$. The migration ability of each test bacteria from the exit site down the material track or in other words, outside of the materials were observed for $24 \mathrm{~h}$

\section{Biofilm forming ability of test organisms: Micro titre plate biofilm assay}

Biofilm forming ability of each test organism is evaluated using the microtitre plate method described by Christensen et al. [13]. In brief, all the test organisms [Staph. aureus, Staph. epidermidis, E. coli, $P$. mirabilis and P. aeruginosa] in Brain Herat Infusion broth (BHIB) were allowed to grow in the 96 well titre plates for $48 \mathrm{~h}$. All the wells are washed with double distilled water and added crystal violet dye to evaluate the remaining adhered organisms. These adhered organisms were considered to be as the biofilm growth on the inner surface of plate. About $100 \mu \mathrm{l}$ of $90 \%$ ethanol was added to each stained well. After incubation the plates were read at a wavelength of $600 \mathrm{~nm}$ using ELISA reader (Braun, Germany). Based on the OD value, the adherence of organism was classified as mentioned in table 1.

Table 1: Classification of biofilm formation

\begin{tabular}{lll}
\hline Mean OD values & Biofilm formation & Biofilm index \\
\hline$<0.120$ & Nil & Non/weak \\
$0.120-0.240$ & Moderately & Moderate \\
$>0.240$ & Strong & High \\
\hline
\end{tabular}

Analysis of Biofilm Expression Genes, icaA, icaB and icaD regulated under the expression of icaR locus

\section{Culturing the test bacteria for DNA extraction}

About $50 \mathrm{ml}$ of LB broth was prepared and the selected test organism (Staphylococcus aureus) was inoculated. Culture tubes were incubated in the appropriate condition $\left(37{ }^{\circ} \mathrm{C}\right.$ for $\left.12 \mathrm{~h}\right)$. Dispensed $5 \mathrm{ml}$ of the culture separately and centrifuged at 8,000 $\mathrm{rpm}$ for $15 \mathrm{~min}$. The pellets were washed in normal saline twice and then suspended in $2 \mathrm{ml}$ normal saline buffer.

\section{Extraction of DNA from the test bacteria}

About $2 \mathrm{ml}$ of test bacterial culture was taken after overnight incubation. The culture suspensions were centrifuged at 10,000 rpm for 15 min to pelletize the cell mass. The supernatant was removed and the cell pellet was incubated on ice till next use. To the obtained pellet $500 \mu \mathrm{l}$ of solution-A ( $25 \mathrm{mmol}$ Tris $\mathrm{Hcl}(39.4 \mathrm{mg}), 50 \mathrm{mmol}$ Glucose $(90.1 \mathrm{mg})$, Lysozyme $(10 \mathrm{mg})$ and Distilled water $(10 \mathrm{ml})$ was added and gently mixed to make a uniform cell suspension. The cell suspension was incubated on ice for $30 \mathrm{~min}$. To the mixture 100 $\mu \mathrm{l}$ of freshly prepared solution-B (0.2M Sodium hydroxide $(30 \mathrm{mg})$, SDS (1\%) and Distilled water $(10 \mathrm{ml})$ was added and vortexed well. The suspension was incubated in ice for 5 min (cells get lysed and the solution becomes clear). About $750 \mu \mathrm{l}$ of solution-C (3 mmol Sodium acetate $(4.08 \mathrm{mg})$ and Distilled water $(10 \mathrm{ml})$ was added and vortexed for $2 \mathrm{~min}$. The suspension was kept in ice for $60 \mathrm{~min}$ (chromosomal DNA and cell material will precipitate into whole viscous clump).

The tubes were centrifuged at $6000 \mathrm{rpm}$ for $10 \mathrm{~min}$ at $4{ }^{\circ} \mathrm{C}$. Transferred the supernatant to fresh eppendorf tube and centrifuged at $10,000 \mathrm{rpm}$ for $10 \mathrm{~min}$ at $4{ }^{\circ} \mathrm{C}$. The supernatant was discarded and to the pellet, $50 \mu \mathrm{l}$ of ice cold ethanol was added along the sides of the tube. The solvent used was removed immediately without disturbing the pellet. The tubes were blot dried using blotting paper by inverting the tube over it. The pellets of DNA were added with $100 \mu \mathrm{l}$ of $1 \mathrm{X}$ TAE buffer and placed in a deep freezer. The DNA precipitate thus obtained was resuspended in bi-distilled water and used as a template for Polymerase Chain Reaction (PCR) method [14].

\section{PCR method for the amplification of the icaA, icaB and icaD sequences}

The pairs of primers were designed for the amplification of the icaA, $i c a B$ and $i c a D$ genes with previously published sequences. The sequences of icaA, icaB and icaD were taken from the GenBank sequence database of the National Center for Biotechnology Information. Primers specific for icaA, icaB and icaD were picked on the gene sequences by the Primer3 program. The primers were synthesized by Chromous Biotech, Bangalore, India.

For the detection of icaA, the following primers were used: 5'CAGTATAACAACATTCTATTGC-3' as the forward primer and 5'GAGAATTGATAAGAGTTCC-3' as the reverse primer, yielding a PCR product of $132 \mathrm{bp}$. For the detection of icaB the following primers were used: 5'-GGTCGTGACATATGAAACC-3' and 5'-GCGTTAGTAAGTGTGTCAC- 3 ' as forward and reverse primer respectively, yielding a PCR product of $121 \mathrm{bp}$. For the detection of icaD the following primers were used: 5'-TTGACAGTCGCTACGAAAAG-3' and 5'-CTCCCAGATAGTAATG3 ' as forward and reverse primer respectively, yielding a PCR product of 142bp (table 2).

PCR reactions were performed using the method described by Arciola et al. [14] with some modifications. The reaction mixture consisted of a reaction buffer [ $50 \mathrm{mmol} \mathrm{KCl,} 10 \mathrm{mmol}$ Tris- $\mathrm{HCl}(\mathrm{pH}$ $9.0), 2,5 \mathrm{mmol} \mathrm{MgCl} 2$ ] in a total volume of $25 \mu \mathrm{l}$ containing $5 \mu \mathrm{l}$ of template DNA (150ng), $0,2 \mathrm{mmol}$ of each deoxynucleotide triphosphate (dATP, dTTP, dGTP, dCTP), 1U Taq DNA polymerase and the above-mentioned primers $(0.5 \mu \mathrm{M}$ each for icaA, icaB and $1 \mu \mathrm{M}$ each for icaD).

DNA amplification was carried out in a thermocycler with the following thermal cycling profile: initial denaturation at $94{ }^{\circ} \mathrm{C}$ for 5 min, followed by 50 cycles of amplification (denaturation at $94{ }^{\circ} \mathrm{C}$ for 30 s, annealing at $59^{\circ} \mathrm{C}$ for $30 \mathrm{~s}$ and extension at $72{ }^{\circ} \mathrm{C}$ for $30 \mathrm{~s}$ ) ending with a final extension at $72{ }^{\circ} \mathrm{C}$ for $1 \mathrm{~min}$. After the first 30 cycles, a further $1 \mathrm{U}$ of Taq DNA polymerase was added. Eight microliters of PCR products were analyzed by electrophoresis in $2 \%$ agarose gel during $50 \mathrm{~min}$ at $80 \mathrm{~V}$. The bands were stained with ethidium bromide $(0.5 \mu \mathrm{g} / \mathrm{ml})$ and observed under UV light. Each run included a DNA marker and a standard ATCC Staphylococcus aureus strain as control.

Table 2: Forward and reverse primers of icaA, icaB and icaD

\begin{tabular}{llll}
\hline S. No. & Target genes & Primer type & Nucleotide sequence \\
\hline 1 & $i c a A$ & Forward & $5^{\prime}$-CAGTATAACAACATTCTATTGC-3' \\
& $i c a A$ & Reverse & $5^{\prime}$-GAGAATTGATAAGAGTTCC-3' \\
2 & $i c a B$ & Forward & $5^{\prime}$-GGTCGTGACATATGAAACC-3' \\
& $i c a B$ & Reverse & $5^{\prime}$-GCGTTAGTAAGTGTGTCAC-3' \\
3 & $i c a D$ & Forward & $5^{\prime}$-TTGACAGTCGCTACGAAAAG-3' \\
& $i c a D$ & Reverse & $5^{\prime}$-CTCCCAGATAGTAATG-3' \\
\hline
\end{tabular}




\section{RESULTS}

Surface colonizing ability of test organisms: Exit-site challenge test

In this present study the surface colonizing ability of test bacteria on the stent sample materials was investigated using exit-site challenge test. All the test organisms used in the research colonized the material surfaces between $24 \mathrm{~h}$ to $48 \mathrm{~h}$. Among the test organisms Staphylococcus epidermidis and Staphylococcus aureus colonized with in 24h; Pseudomonas aeruginosa, Escherichia coli and Proteus mirabilis colonized the stent surface after $48 \mathrm{~h}$.
Biofilm forming ability of test organisms: microtitre plate biofilm assay

In table 3, the optical density (OD) values and biofilm index of the test organisms were presented based on the biofilm classification described by Christensen et al., (1985). Out of five test organisms, three showed significant biofilm index value indicating as strong biofilm producers. All the three organisms showed OD values $>0.240$ [Staph. aureus (0.290), E. coli $(0.250)$ and Staph. epidermidis (0.270)]. The differences in OD values observed during the analysis were due to the amount of crystal-violet (dye) absorbed by the test organisms in the microtitre well. Appropriate control was maintained throughout the test.

Table 3: Assessing the biofilm forming capability of test bacteria using standard Microtitre plate biofilm assay

\begin{tabular}{lll}
\hline Test bacteria & Biofilm formation (OD 570 $\mathbf{n m}$ ) & Biofilm index \\
\hline Escherichia coli & 0.25 & High \\
Staphylococcus aureus & 0.29 & High \\
Staphylococcus epidermidis & 0.27 & High \\
\hline
\end{tabular}

\section{PCR detection of icaA, icaB and icaD genes}

Among the three high biofilm producing organism, Staphylococcus aureus showed highest biofilm index value in the microtitre plate assay. Hence, the bacterium was selected to analyse the presence of biofilm expressing genes icaA, icaB and icaD using the specific primers with the aid of polymerase chain reactions.

During the analysis, all the three icaA, icaB and ica genes were identified. In fig. 1, the bands obtained for the respective genes were presented in comparison with the icaA bands of a reference strain. In Lane-1, marker genes with known molecular weight were clearly observed. In Lane-2, 124bp icaA bands of reference strain were observed. In Lane-3, 4 and 5, 132 bp, 121 bp and 138bp bands of icaA, ica $\mathrm{B}$ and ica genes were observed respectively.

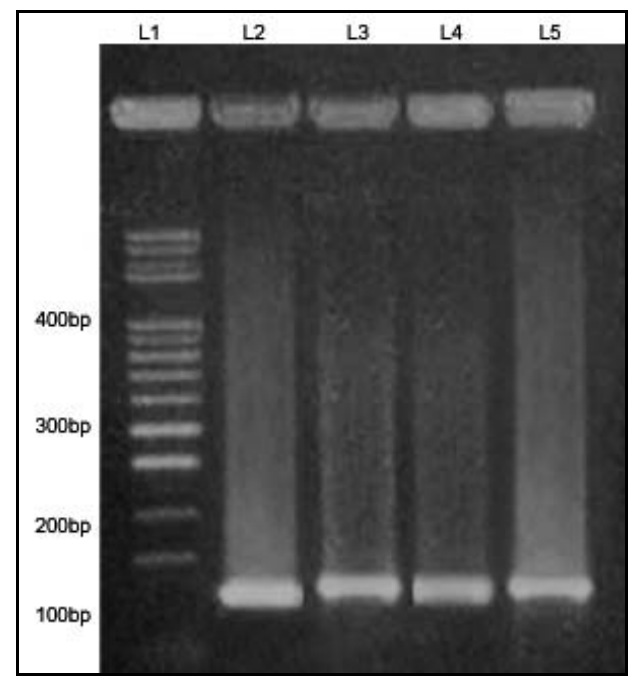

Fig. 1: Analysis of biofilm expression genes icaA, icaB and icaD genes of the test bacterium staphylococci, Lane-1: DNA marker, Lane-2: $124 \mathrm{bp}$ band of icaA from DNA sample of reference organism, Lane-3: 132 bp band from DNA sample of biofilm producing test bacterium, Staphylococci with primers for icaA., Lane-4: $121 \mathrm{bp}$ band from DNA sample of biofilm producing test bacterium, Staphylococci with primers for icaB, Lane-5: $138 \mathrm{bp}$ band from DNA sample of biofilm producing test bacterium, Staphylococci with primers for icaD

\section{DISCUSSION}

In the last two decades, with the increasing use of indwelling medical devices, nosocomial infections caused by Gram-positive bacteria, in particular Staphylococcus spp., have become more prevalent as a cause of hospital-acquired infection [15]. Biomaterials associated infection is the most common issue associated with the biomaterial implants regardless of its form or function. Bacteria form colonies and this result in the formation of biofilm on the surface, making the infection unreceptive to antibiotics and host defense mechanisms. Hence, the implant needs to be removed [16]. Also, these factors make the clinical treatment extremely difficult in the infected persons. Biofilm production is an important pathogenic factor which facilitates adherence of microorganisms to medical devices and protects them from the host immune system and antimicrobial therapy [17]. Biofilms constitute a reservoir of pathogens which are associated with the resistance to antimicrobial agents and cause chronic infections [18]. The biofilm development process requires polysaccharide intercellular adhesin, which is synthesized by the enzymes encoded by the intercellular adhesion cluster (ica) [19]. Early detection and management of biofilm-forming staphylococci can be one of the essential steps towards the prevention and management of deviceassociated nosocomial infections [20].

In preliminary exit-site challenge test, the migration or growth of the test organism around the materials after incubation was indicated by tracking of bacteria along the abluminal surface. The inoculated site was considered to be as skin exit-site and migration and growth of the organisms along the media surface was considered to be as the tissue tunnel and tissue surroundings. Bayston et al., (2009) reported that the most frequent routes of catheter associated infection are from the skin exit site, the tissue tunnel associated with the catheter and the catheter lumen. Similar exit-site challenge model under in vitro condition used by Bayston et al., (2009) showed surface colonization of methicillin resistant Staphylococcus aureus (MRSA) on the CSF silicone shunts surface. Two significant biofilm producing organisms, Staphylococcus epidermidis and Staphylococcus aureus produced biofilm within $24 \mathrm{~h}$ in the present study. The reason may be the expression of icaR gene encoding a transcriptional repressor involved in environmental regulation of the ica operon expression and biofilm formation in S. epidermidis [21]. Murugan et al.,[22] detected that cupA genes were responsible for biofilm formation in P. aeruginosa. The obtained results were thus considered as the preliminary test to determine the surface colonizing ability of the test organisms.

Microtitre plate (MTP) biofilm assay confirmed the strong biofilm index for Staphylococcus epidermidis and Staphylococcus aureus after expressing the growth within $24 \mathrm{~h}$ during exit-site challenge test. The differences in OD values were due to the amount of crystal-violet (dye) absorbed by the test organisms in the microtitre well. This method was found to be most sensitive, accurate and reproducible screening method for the detection of biofilm formation. The method has the advantage of being a quantitative model to study the adherence of organism on biomedical devices. In this test, even though all the test organisms were proved to be high biofilm producers, Staphylococcus aureus was selected for PCR analysis due to its common clinical complications in the medical sciences. 
In the MTP assay, with BHIB used as standard growth medium, all the three out of five positive strains exhibited high biofilm index values. This is in agreement with the observations of other investigators who found that few or no biofilm-producing isolates could be detected using this medium. Surprisingly, supplementation of BHIB medium with different sugars (BHIB 2\% sucrose, BHIB 1\% glucose) increased biofilm formation, and $34 \%$ of the studied isolates formed a biofilm in at least one of the used media [23]. Furthermore, two isolates of staphylococci icaD+and icaA-did not form a biofilm in both media. These observations suggested that biofilm formation in staphylococcus spp is strongly dependent on growth conditions, and indicated that the use of various sugar supplementations is essential for biofilm formation [24].

In the present study, high biofilm producing staphylococci strains $(S$. aureus) were subjected to PCR for determining icaA and icaD genes to identify and confirm biofilm producing strains. Results revealed that both icaA and icaD genes were present in the test organism. The results confirm the fact that both genes are part of one operon and so the entire operon was present in the organism; indicating the important role of ica genes as virulence markers in staphylococcal infections. The gene expression of virulence makers were reported by many researchers [25-27]. The expression of this gene alone induces low enzymatic activity and production of low amount of poly-saccharide. However, the simultaneous expressions of ica $\mathrm{A}$ and icaD promote a significant increase in $\mathrm{N}$-acetylglucosaminyltransferase, the enzyme involved in the synthesis of $\mathrm{N}$ acetylglucosamine oligomers in other words called capsular polysaccharide. These results are in agreement with those of De Silva et al. [28]. Arciola et al. [29] reported that all S. aureus and $S$. epidermdis biofilm positive strains isolated from intravenous catheters were positive for icaA and icaD genes and that these genes are required for full slime synthesis, which is in agreement with our results.

\section{CONCLUSION}

Implant associated infections caused by Staphylococcus aureus and other nosocomial pathogens were reported to be highly complicated to treat in the individuals. The major pathogenic factor is the ability to produce an extracellular slime and form a biofilm, thus making the clinical treatment extremely difficult. Due to the clinical complications caused by biofilm producing organism in the indwelling medical devices, early detection of biofilm expressing genes in the target organism shall be considered as the essential approach towards the prevention and management of deviceassociated infections. Hence, genes responsible for the biofilm formation in the target organisms were investigated in the present study. The presence of the intercellular adhesion biofilm genes (icaA, $i c a B$ and $i c a D$ ) was determined by the Polymerase Chain Reaction method. In exit-site challenge test, all the test organisms colonized the inner and outer surface of stent materials with in $24 \mathrm{~h}$ to $48 \mathrm{~h}$. Staphylococcus aureus and Staphylococcus epidermidis showed high biofilm index values ( 0.29 and 0.27$)$ in the microtitre plate method. Investigation of biofilm gene studies revealed the presence of all the three ica genes (icaA, icaB and icaD) in Staphylococcus aureus after subjecting with polymerase chain reaction method. During the investigation of biofilm expressing genes, the test organism showed three bands corresponding to icaA (132bp), icaB (121bp) and icaD (138bp) very predominantly. As per the framed objective, it is concluded that, the virulence factors contributing to the development of infections can be revealed by understanding the presence of biofilm expression genes in the target organisms. This would also prevent dissemination of virulent bacteria in the health care centre; method also considered significant to detect healthy carriers of slime-producing staphylococci.

\section{CONFLICT OF INTERESTS}

Authors declare no conflict of interes

\section{REFERENCES}

1. Wilking JN, Zaburdaev V, de Volder M, Losick R, Brenner MP, Weitz DA. Liquid transport facilitated by channels in Bacillus subtilis biofilms. Proc Natl Acad Sci 2013;110:848-52.
2. Thambidurai Punitha, Kannaiyan Moorthy, Ponnusamy Vijayalakshmi, Raja Vinodhini, Selvam Saranya, Murugesan Bhuvaneshwari, et al. In vitro antibacterial activity of essential plant oils against biofilm forming methicillin resistant Staphylococcus aureus. Asian J Pharm Clin Res 2014;7 Suppl 1:220-5.

3. Cho S, Naber K, Hacker J, Ziebuhr W. Detection of the icaADBC gene cluster and biofilm formation in Staphylococcus epidermidis isolates from catheter-related urinary tract infections. Int J Antimicrob Agric 2002;19:570-5.

4. Mack D. Molecular mechanisms of Staphylococcus epidermidis biofilm formation. J Hosp Infect 1999;43:113-25.

5. Cafiso V, Bertuccio T, Santagati M, Campanile F, Amicosante G, Perilli MG, et al. Presence of the ica operon in clinical isolates of Staphylococcus epidermidis and its role in biofilm production. Clin Microbiol Infect 2004;10:1081-8.

6. Boucher HW, Talbot GH, Bradley JS, Edwards JE, Gilbert D, Rice LB, et al. Bad bugs, no drugs: No eskape! An update from the infectious diseases society of America. Clin Infect Dis 2009:48:1-12.

7. Nasr RA, Abu Shady HM, Hussein HS. Biofilm formation and presence of icaAD gene in clinical isolates of staphylococci. Egypt J Med Human Genet 2012;13:269-74.

8. El Farran C, Sekar A, Balakrishnan A, Shanmugam S, Arumugam P, Gopalswamy J. Prevalence of biofilm-producing Staphylococcus epidermidis in the healthy skin of individuals in Tamil Nadu, India. Indian J Med Microbiol 2013;31:19-23.

9. Atshan SS, Shamsudin MN, Sekawi Z, Lung LTT, Hamat RA, Karunanidhi A, et al. Prevalence of adhesion and regulation of biofilm-related genes in different clones of Staphylococcus aureus. J Biomed Biotech 2012;5:10-7.

10. Agarwal A, Jain A. Glucose and sodium chloride induced biofilm production and ica operon in clinical isolates of staphylococci. Indian J Med Res 2013;138 Suppl 2:262-6.

11. Mertens A, Ghebremedhin B. Genetic determinants and biofilm formation of clinical Staphylococcus epidermidis isolates from blood cultures and indwelling devises. Eur J Med I 2013;3:111-9.

12. Bayston R, Fisher LE, Weber K. An antimicrobial modified silicone peritoneal catheter with activity against both gram positive and gram negative bacteria. Biomat 2009;30 Suppl 18:3167-73.

13. Christensen GD, Simpson WA, Younger JA, Baddour LM, Barrett FF, Melton DM. Adherence of coagulase negative staphylococi to plastic tissue cultures: a quantitative model for the adherence of staphylococci to medical devices. J Clin Microbiol 1985;22:9961006.

14. Aricola CR, Commpaoccia D, Baldassari L, Donati ME, Gamberini S, Montanaro L. Detection of biofilm formation in Staphylococcus epidermidis from implant infections comparisons of a PCR method that recognize the presence of ica genes with two classic phenotypic methods. J Biomed Mater Res 2005;76 Suppl 2:425-30.

15. Angela Revelas. Healthcare-associated infections: a public health problem. Niger Med J 2012;53:59-64.

16. Sivarama Krishnan Rajaraman, Mallika Jainu, Gnanaprakash Dhakshinamoorthy. Ocimum Basilicum L. essential oil coated biomaterial surfaces prevent bacterial adhesion and biofilm growth. Asian J Pharm Clin Res 2016:9:379-84.

17. Khan F, ShuklaI RM, Mansoor T, Sharma SC. Detection of biofilm formation in Staphylococcus aureus. Does it have a role in treatment of MRSA infection? Trends Med Res 2011;10:1-8.

18. Seif El-Din S, El-Rehewy MS, Ghazaly MM, Abd-Elhamid MH. Biofilm formation by blood stream staphylococcal isolates from febrile pediatric cancer patients at South Egypt cancer institute. J Am Sci 2011;7 Suppl 1:674-86.

19. Gad GFM, El-Feky MA, El-Rehewy MS, Hassan MA, Abolella H, El-Baky HMA. Detection of icaA, icaD genes and biofilm production by Staphylococcus aureus and Staphylococcus epidermidis isolated from urinary tract catheterized patients. J Infect Dev Ctries 2009;3:342-51.

20. Namvar AE, Asghari B, Lari AR. Detection of the intercellular adhesion gene cluster (ica) in clinical Staphylococcus aureus isolates. Hyg Inf Cont 2013;8 Suppl 1:2196-226.

21. Conlon KM, Humphreys HGarQ P. icaR encodes a transcriptional repressor involved in environmental regulation of ica operon expression and biofilm formation in Staphylococcus epidermidis. J Bacteriol 2002;184 Suppl 16:4400-8. 
22. Murugan K, Selvanayaki K, Al-Sohaibani S. Antibiofilm activity of Andrographis paniculata against cystic fibrosis clinical isolate Pseudomonas aeruginosa. World J Microbiol Biotechnol 2011;27:1661-8.

23. Johannes KM, Knobloch MA, Horstkotte H, Dietrich $M$ Evaluation of different detection methods of biofilm formation in Staphylococcus aureus. Med Microbiol Immunol 2002;191:101-6.

24. Mathur T, Singhal S, Khan S, Upadhyay DJ, Fatma T, Rattan A. Detection of biofilm formation among the clinical isolates of Staphylococci: An evaluation of three different screening methods. Indian J Med Microbiol 2006;24 Suppl 1:25-9.

25. Dobinski S, Bartscht K, Mack D. Influence of Tn917 insertion of transcription of the icaADBC operon in six biofilm-negative transposon mutants of Staphylococcus epidermidis. Plasmid 2002;47:10-7
26. Oliveira A, de Lourdes RS, Cunha M. Comparison of methods for the detection of biofilm production in coagulase-negative staphylococci. BMC Res Notes 2010;1:253-60.

27. Gad G, El-Feky M, El-Rehewy M, Hassan M, Abolella H, Abd ElBaky R. Detection of icaA, icaD genes and biofilm production by Staphylococcus aureus and Staphylococcus epidermidisisolated from urinary tract catheterized patients. J Infect Dev Countries 2009;3 Suppl 5:342-51.

28. De Silva GD, Kanatazanou M, Massey RC, Wikinson AR, Day NP, Peacock SJ. The ica operon and biofilm production in coagulase negative staphylococci associated with carriage and disease in neonatal intensive care unit. J Clin Microbiol 2002;40:382-8.

29. Arciola CR, Baldassarri L, Montanaro L. Presence of $i c a A$ and $i c a D$ genes and slime production in a collection of staphylococcal strains from catheter-associated infections. J Clin Microbiol 2001;39:2151-6. 